\title{
"Um sonho cortado pela metade...": Estudo de caso sobre o impacto da prematuridade e da deficiência visual do bebê na parentalidade
}

\author{
Carla Meira Kreutz. \\ Universidade Luterana do Brasil \\ Cleonice Alves Bosa \\ Universidade Federal do Rio Grande do Sul
}

\begin{abstract}
Resumo
Quando a prematuridade culmina com um diagnóstico de retinopatia da prematuridade com perda da visão, os pais sofrem um duplo impacto. O presente estudo teve por objetivo investigar as reações emocionais dos pais nesse contexto e seu impacto na parentalidade. Para tanto, pais de uma menina de 13 meses foram entrevistados conjuntamente. Os dados foram examinados, utilizando-se a análise de conteúdo. Os resultados mostraram um choque dos pais com a aparência do bebê prematuro, o medo da morte do bebê, dificuldades para a compreensão do diagnóstico, negação, culpa, sentimentos hostis em relação à equipe médica e diminuição da autoeficácia do casal como pais. Por outro lado, identificou-se uma busca de reorganização do casal e alegrias frente à parentalidade.
\end{abstract}

Palavras-chave: prematuridade; deficiência visual; impacto; parentalidade; bebê.

\begin{abstract}
"A dream cut in half...": A case study of the impact of prematurity and the vision impairment of the baby on parenthood. Prematurity in conjuction with diagnosis of premature retinopathy aimed to with loss of vision cause, in parents a double impact. This study aimed to investigate the emotional parents reactions in this context and its impact on parenthood. Parents of a 13 months old baby girl were interviewed together. The data was examined by means of content analysis. The results revealed that parents were in shock with the appearance of the premature baby, faced fear of the baby's death, difficulty to understand the diagnosis, denial, guilt, hostile sentiments toward the medical team and diminished self-efficacy as parents. On the other hand, a couple's reorganization and happiness in the face of parentality, were also identified.
\end{abstract}

Keywords: prematurity; vision impairment; deficiency; impact; parenthood; baby.

\section{Resumen}

“Un sueño cortado al medio...": Estudio de caso sobre el impacto de la prematuridad y de la discapacidad visual del bebé en la parentalidad. Cuando la prematuridad culmina con un diagnóstico de la retinopatía, con pérdida de la visión, los padres sufren un doble impacto. El presente estudio tuvo como objetivo investigar las reacciones emocionales de los padres en este contexto y su impacto en la parentalidad. Para ello, se entrevistó conjuntamente a los padres de una niña de 13 meses. Los datos fueron analizados mediante análisis de contenido. Los resultados mostraron un choque de los padres con la aparencia de un bebé prematuro, miedo de la muerte del bebé, dificultades para comprender el diagnóstico, negación, culpa, sentimientos de hostilidad hacia el equipo médico y la disminucíon de la auto-eficacia de la pareja como padres. Por otra parte, fue identificada una búsqueda de reorganización de la pareja y de alegrías por la parentalidad.

Palabras clave: prematuridad; discapacidad visual; impacto; parentalidad; bebé.

Deficiência visual do bebê: A retinopatia da prematuridade como um duplo impacto nos pais

A deficiência visual pode ser dividida em dois grupos. $\mathrm{O}$ primeiro inclui os indivíduos com baixa visão, que têm sido considerados aqueles que apresentam diminuição das suas respostas visuais, mesmo após tratamento e/ou correção óptica convencional, e uma acuidade visual menor que 6/18 à percepção de luz, ou um campo visual menor que 10 graus do seu ponto de fixação. O segundo grupo inclui indivíduos com cegueira, os quais apresentam acuidade visual baixa e podem também 
apresentar ausência de percepção da luz (Resnikoff et al., 2004; WHO, 1993).

No caso de deficiência visual grave ou cegueira em bebês, a retinopatia da prematuridade (ROP) é a mais comum, atingindo pelo menos 50.000 crianças no mundo, alcançando proporções epidêmicas em países sul-americanos, incluindo o Brasil (Gilbert, 2008). Um estudo brasileiro, no estado de Santa Catarina, mostra a alta prevalência (20\%) da ROP em bebês prematuros (Bonotto, Moreira, \& Carvalho, 2007). Tais números são preocupantes, ainda mais se considerarmos que o exame precoce da visão, durante um período crítico, nas Unidades de Tratamento Intensivo Neonatal (UTIN's) poderia evitar a cegueira (Mousavi et al., 2009).

O nascimento é considerado prematuro quando ocorre antes das 37 semanas de gestação (WHO, 1999). Nascem, no mundo, 13 milhões de crianças prematuras anualmente e morrem cerca de um milhão de neonatos (Simmons, Rubens, Darmstadt, \& Gravett, 2011). A prematuridade também afeta a qualidade de vida daqueles que sobrevivem a ela e suas famílias, uma vez que comumente deixa sequelas (Simmons et al., 2011).

Andreani, Custódio e Crepaldi (2006) afirmam que as famílias de bebês prematuros têm nas redes de apoio uma grande oportunidade para reduzir o impacto do risco e oferecer oportunidade de um melhor enfrentamento da situação. São comuns nas mães sentimentos de culpa e impotência, percepção de que o vínculo mãe-bebê estava afetado, o que gerava tristeza e solidão (Rossel, Carreño, \& Maldonado, 2002). Mães de bebês prematuros também referiram a percepção de seu bebê como pequeno e disforme, temendo sua fragilidade (Arnold et al., 2013; Rossel et al., 2002), assim como referiram dificuldades de comunicação com o sistema de saúde (Rossel et al., 2002). A experiência traz também, muitas vezes, a presença de sintomas de estresse pós-traumático e a sensação de maior dificuldade de interação com seu bebê (Morisod-Harari, Borghini, Hohlfeld, Forcada-Guex, \& Muller-Nix, 2013).

Forcada-Guex, Borghini, Pierrehumbert, Ansermet e Muller Nix (2011) também apontaram que as mães de bebês a termo são mais propensas a seguir um padrão interativo mais cooperativo. O pai também é visto como podendo ter uma sobrecarga sobre si (Rossel et al., 2002) ou sentir-se excluído e confuso sobre seu papel (Arnold et al., 2013). Por outro lado, Donohue, Maurin, Kimzey, Marilee e Strobino (2008), investigando pais de bebês prematuros quando estes já estavam com 12 a 18 meses, concluíram que os pais percebiam ter uma boa qualidade de vida, possivelmente por terem encontrado um sentido de vida em suas experiências.

Poucos estudos são encontrados em relação ao impacto dos pais frente ao diagnóstico da DV de seu filho. Um deles investigou 14 mães de crianças com DV e mostrou que, perante o diagnóstico, surgem sentimentos tais como tristeza, medo e decepção, assim como angústia, culpa, impotência, ansiedade, raiva e revolta (Nobre, Montilha, \& Temporini, 2008). Lopes, Salomão, Berezovsky e Tartarella (2009), ao investigarem o impacto do diagnóstico da DV, encontraram diminuição da qualidade de vida nas crianças, proporcionalmente à gravidade da DV, quando comparadas a um grupo controle. Investigando os sentimentos dos pais em relação ao diagnóstico e sua compreensão disso, Figueiredo, Paiva e Silva e Nobre (2009) entrevistaram 10 mães de crianças com baixa visão. De forma similar ao estudo de Nobre et al. (2008), eles identificaram medos, desespero, tristeza, raiva, revolta, não aceitação e culpa, mas também superação e ajustamento. Os sentimentos das mães estão interligados ao seu contexto sociocultural, envolvendo suas crenças e expectativas em relação à doença. Os resultados também apontaram dificuldades na compreensão do problema de visão do filho. Dessa maneira, as autoras sinalizam para a importância da maneira como o diagnóstico é transmitido à família pelo médico, sendo necessário levar em consideração as condições culturais, econômicas e emocionais dos pais.

Tröster (2001) comparou mães de crianças com DV e de crianças videntes e sem outras deficiências e concluiu que o nível de estresse nas primeiras é maior do que nas outras. O autor afirma que esses achados estão relacionados ao fato de que, muitas vezes, o comprometimento da criança dificulta a sua cooperação nas atividades diárias. Tal perspectiva é corroborada pelo estudo de Andrew e Sullivan (2010), os quais apontam as dificuldades de previsibilidade da criança com DV ao ser alimentada, o que dificulta essa rotina diária dos pais. Pais de crianças com DV apresentam muitas preocupações relacionadas ao futuro do filho, com a própria vida pessoal, com auxílio profissional adequado às necessidades da criança, com o pouco tempo disponível para eles como indivíduos e como casal, assim como com questões financeiras (Leyser, Heinze, \& Kapperman, 1996).

\section{O nascimento de um bebê com deficiência: Modelos teóricos}

Há um processo de construção do bebê imaginado (Cramer \& Palácio-Espasa, 1993; Soulé, 1987; Stern, 1997). De fato, estudos têm mostrado o quanto os pais sonham com um bebê perfeito (Ferrari, Piccinini, \& Lopes, 2007). Uma vez que o bebê imaginado está interligado a uma série de aspectos relacionados à vida psíquica da mãe (Ferrari et al., 2007), é necessária a elaboração de um "luto" por ele, quando a mãe se defronta com o bebê real (Irvin et al.,1993).

Drotar, Maskiewicks, Irvin, Kennell e Klaus (1975) formularam um modelo hipotético de reações ao nascimento de uma criança com malformações congênitas (que vem sendo utilizado até os dias de hoje). Os autores citam cinco estágios, os quais não ocorrem necessariamente nessa ordem: a) choque; $b$ ) descrença (negação); c) tristeza, cólera e ansiedade; d) equilíbrio; e) reorganização.

O primeiro estágio foi descrito como um choque esmagador com perturbações abruptas de seus estados "normais" de sentimentos. O segundo estágio envolve uma tentativa de evitar admitir que o seu bebê tem uma anomalia. $\mathrm{O}$ terceiro estágio, de tristeza, cólera e ansiedade, foi caracterizado como um período de reações emocionais de muito desânimo, nervosismo e com muito choro. Sentimentos de raiva em relação a qualquer pessoa ou mesmo ao bebê ou a si mesmos foram também relatados por pais nesse estágio. No quarto estágio, há uma diminuição de sentimentos de angústia e um maior ajustamento à situação e maior capacidade para cuidar do bebê, mas ainda com muita tristeza. Por fim, o estágio de reorganização é descrito como um 
momento em que os pais lidam com a nova responsabilidade pelos problemas de seus filhos. É um momento em que os pais se sentem mais capazes, ao perceberem que estão tendo um manejo bem-sucedido (Irvin et al.,1993).

No caso da ROP, o desafio para os pais é intensificado, pois eles enfrentam primeiramente todo o medo e estresse em função da prematuridade e, quando cessa o risco da morte pela prematuridade, os pais passam a um novo desafio: conhecer, compreender e aprender a lidar com o diagnóstico da deficiência visual. Bradford (1997) desenvolveu um metamodelo para compreender o impacto da doença crônica na família, integrando noções sistêmicas e cognitivas. Para o autor, a adaptação depende de quatro fatores: 1) o padrão de interação familiar; 2) a comunicação entre a equipe de saúde e a família/paciente; 3 ) o ambiente de cuidados de saúde e 4) as crenças da família sobre saúde e doença. Todos esses fatores interagem e se influenciam mutuamente.

Os estudos revisados indicam haver pesquisas que enfatizam o impacto da prematuridade nos pais e outros estudos que investigam os sentimentos e reações dos pais frente à deficiência visual, mas a investigação desse duplo impacto carece de investigação. Estudos específicos sobre DV nas áreas de oftalmologia, desenvolvimento e educação são expressivos no país (Fortes Filho, Barros, Coelho da Costa \& Procianoy, 2007; Fortes Fillho et al., 2009; Laplane \& Batista, 2008; Melamed, 2009; Nuernberg, 2008; Souza \& Batista, 2008). Nesse sentido, o presente estudo, através de uma pesquisa qualitativa e de caráter exploratório, na qual foi empregado o método de estudo de caso único $^{1}$, teve por objetivo investigar as reações emocionais dos pais em relação ao nascimento prematuro do filho, seguido de um diagnóstico tardio de ROP que culmina com uma deficiência visual grave (cegueira) no bebê, e seu impacto na parentalidade.

\section{Método}

\section{Participantes}

Um casal com uma filha de um ano e dois meses com DV grave (cegueira), bilateral, sem percepção de luz, a qual nasceu prematuramente e foi diagnosticada com retinopatia da prematuridade (ROP 5) aos três meses de vida.

\section{Instrumentos}

Ficha de dados da família e da saúde do bebê. Visou a coletar informações sobre a deficiência visual do bebê, dados demográficos e outros.

Entrevista sobre a experiência da maternidade/paternidade antes da intervenção. Teve a duração de uma hora e trinta minutos e visou a investigar aspectos tais como: impacto do diagnóstico, sentimentos, dificuldades, expectativas dos pais e outros. Os pais foram entrevistados conjuntamente em um consultório psicológico somente para fins dessa pesquisa.

\section{Procedimentos de coleta e de análise de dados}

Os pais foram contatados em um hospital público de uma capital da região sul do país e convidados a participar do presente estudo. Foi agendado um encontro, foram apresentadas explicações detalhadas sobre o projeto, assinado o Termo de Consentimento Livre e Esclarecido e aplicados os instrumentos. A escolha dos participantes ocorreu no ambulatório de oftalmologia do hospital, quando a primeira família que se enquadrava nos critérios de inclusão na pesquisa chegou ao serviço na época estabelecida para o recrutamento (janeiro de 2008). A entrevista sobre a experiência de maternidade/paternidade foi gravada, transcrita e analisada mediante análise de conteúdo (Bardin, 1977). As categorias temáticas são derivadas dos relatos dos pais. Os estágios do modelo hipotético de Drotar et al. (1975) foram utilizados para a compreensão analítica dos temas trazidos pelos pais. Os nomes são fictícios para a preservação da identidade dos participantes.

\section{Resultados e discussão}

\section{Identificação da família}

Ana, uma mulher de 36 anos, com curso superior completo, e Edson, um homem de 35 anos, com $2^{\circ}$ grau completo, quando da realização da entrevista, trabalhavam em uma pequena empresa própria e viviam no interior do Rio Grande do Sul. Após oito anos de coabitação, engravidou de Kate, primeira filha do casal.

A gestação foi planejada e, inclusive, Ana fez tratamento hormonal para engravidar. O exame de gravidez foi aguardado com expectativa pelo casal e a notícia recebida com alegria, como exemplifica o relato a seguir: "Meu Deus!!! Saí pulando (...) sabe, uma coisa muito boa, muito boa!" (Mãe)

Nesse momento, é possível identificar o orgulho e a excitação dos pais ao perceberem, entre outros aspectos, que são capazes de gerar um bebê. A construção do bebê ideal ganha relevo nesta etapa e, como afirma Stern (1997), é sustentada pelos sonhos e esperanças de um bebê "perfeito", saudável e tão ansiosamente esperado, que irá completar a "felicidade" do casal. No momento da constatação da gravidez, parecia ainda não haver espaço para os temores.

Durante a gestação, até a $26^{\underline{a}}$ semana, tudo estava correndo bem. O casal frequentou curso de gestantes e não foram reportados outros estressores nessa etapa. No entanto, na $26^{\mathrm{a}}$ semana, a bolsa rompeu e o bebê nasceu prematuramente de parto vaginal com $695 \mathrm{~g}$.

\section{A prematuridade: frustração, medo da morte e de deficiências}

Não surpreendentemente, os pais relatam que a experiência da prematuridade foi sentida como uma intensa frustração. $\mathrm{O}$ bebê (e a gravidez) ideal deu lugar ao bebê real, que os pais ainda têm que aprender a reconhecer e a se relacionar, e à perda do corpo "grávido", conforme ilustra a fala materna.

Eu sonhava com a barriga grande, os pés inchados... (...) Então, na verdade eu nem senti minha gravidez. Quando pensei em começar a usar aquelas roupas de grávida,(...) eu nem cheguei a usar. (...) Quando começou mal e mal a aparecer, aí foi uma desilusão, sabe, total, porque... um sonho que a gente imagina, um sonho cortado pela metade. É, um sonho cortado pela metade. [grifo nosso] (Mãe) 
Para Soulé (1987), as mães vivem intensamente as mudanças fisiológicas da gravidez, que possuem um correspondente emocional em termos de expectativas e representações psíquicas. Brazelton (1998) refere que a perda precoce do corpo grávido com o nascimento prematuro é sentida como um golpe para a autoestima materna. Isso está relacionado ao fato de que essa perda destitui a gestante do papel de cuidadora em uma maternagem sadia, desfazendo a possibilidade de vivenciar os sonhos construídos.

Kate necessitou de cuidados intensivos na UTIN por 100 dias. Durante a internação, sofreu duas infecções generalizadas. Ao sair da UTIN Kate ficou cerca de uma semana no quarto. Os pais relatam que esse período foi extremamente difícil, aparecendo a angústia e o medo de perder o bebê, conforme ilustra a sequência do diálogo a seguir.

Mãe: Logo que a Kate nasceu, o médico disse que as primeiras 72 horas eram imprevisíveis. Poderia acontecer de tudo, e a qualquer momento. Então foi uma coisa assim, de muito medo, muito medo, muita angústia, muita, muito tudo, sabe... uma angústia muito grande, muito grande mesmo!

Pai: E tinha outros bebês ali, muito graves, aqueles dois...

Mãe: É, um durou quatro horas e o outro duas!

O medo de perder o bebê também aparece no relato da mãe quando conta de sua angústia para ver sua filha, com medo de que a morte chegasse antes. "Eu queria ir ver porque eu tinha medo que, de repente, não fosse mais ver a Kate. E daí fiquei com medo e queria porque queria ir ver." (Mãe)

Durante a internação, os pais passaram por diversos momentos em que a saúde da filha era delicada, e o temor da morte estava sempre presente. Os relatos anteriormente citados mostram o contraste dos momentos de alegria pela notícia da gestação e a dor e o medo pela prematuridade. A definição da mãe em relação à sua frustração com o nascimento prematuro - "um sonho cortado pela metade" - clareia a vivência da prematuridade e mostra o quanto o nascimento prematuro faz os pais se defrontarem com uma situação de surpresa, de despreparo para a parentalidade - uma "família prematura" (Andreani et al., 2006).

Esses resultados estão de acordo com aqueles de Rossel et al. (2002), quando afirmam que a prematuridade e a consequente hospitalização geravam temores, especialmente da morte. $\mathrm{O}$ temor dos pais tem base na realidade, uma vez que a literatura aponta que a mortalidade e as deficiências apresentam um índice elevado nos casos de prematuridade, em especial naqueles bebês nascidos com muito baixo peso (Simmons et al., 2011).

O casal relata que houve uma decepção com a aparência da filha, conforme diálogo a seguir:

Mãe: Ai, eu não, não sabia o que eu tava vendo, era uma coisa, uma miniatura, tudo tão, coisa esquisita, coisa... uma cabecinha assim (faz um gesto com as mãos), menos do que esta bolinha aqui. (...) Era uma coisa muito esquisita, uma coisa feia.

Pai: Mas toda formadinha por fora... tá louco!

O peso e o tamanho do bebê foram aspectos que deixaram os pais de Kate muito impressionados, o que vem ao encontro do estudo de Rossel et al. (2002). A primeira fase de reações emocionais ao diagnóstico de uma deficiência (Drotar et al., 1975) se assemelha aos sentimentos de angústia e medo presentes ao nascimento e à hospitalização, relatados no presente estudo, perante a prematuridade. Isso pode ser explicado pelo fato de a prematuridade também ser um choque.

O primeiro contato com um bebê tão pequeno e com a saúde tão frágil mostrou ser um abalo em relação ao filho imaginado que os pais tinham em mente. A elaboração do luto torna-se ainda mais complexa, pois é um luto por um bebê diferente daquele que tinham em mente, por uma gestação que não foi até o fim e por um parto tranquilo e, junto a tudo isso, a luta pela sobrevivência do bebê.

\section{O impacto do diagnóstico da deficiência visual: Choque, confusão, raiva, culpa e desamparo}

$\mathrm{O}$ diagnóstico de ROP foi realizado quando Kate estava com três meses (próximo de quando estariam completando as 40 semanas de gestação). Semanas depois, a família foi encaminhada à capital, mas foram informados de que já havia passado a época de se tentar aplicar o tratamento com laser. No entanto, ainda foi realizada uma cirurgia, com poucas chances de sucesso, e o resultado não foi o esperado. O conhecimento do diagnóstico se deu de forma gradativa, denotando que essa notícia ainda estava sendo processada.

O casal conta que ainda alimentava esperanças de ter resultados da cirurgia realizada quando foi surpreendido com a sugestão de uma prótese, procedimento que implica a retirada do globo ocular. Esse fato os deixou muito assustados e com receio de não poder usufruir de recursos imaginados, no futuro, tais como olho biônico ${ }^{2}$ ou outros. O casal relata que o período da busca de tratamento na capital foi extremamente complicado, quando foram sendo encaminhados de um hospital a outro, de um profissional a outro. Hospedavam-se em locais oferecidos pela Secretaria de Saúde de seu município.

Andreani et al. (2006) afirmam que, sendo a prematuridade uma situação mobilizadora de estresse para a família, as redes de apoio se constituem de grande importância para reduzir o impacto do risco e oferecer oportunidade de desenvolvimento saudável para a família. Depreende-se então, que a falta dessa pode colocar em risco a saúde mental dos pais e o consequente desenvolvimento do bebê.

Sobre a reação de confusão e dúvidas a respeito do diagnóstico, a sequência de falas dos pais ilustra esta experiência:

Mãe: A gente não sabe até então se ela enxerga, ou quanto que ela enxerga!?

Pai: Isto eles não dizem.

Mãe: Isso a gente gostaria de ouvir.

Pai: (...) E a cirurgia? Dizem que tá bem! Será que é verdade? O que é que tá bem a gente não sabe, eles não falam, não sabe o quanto ela vai enxergar, se ela vai enxergar, se não vai? É ela que vai falar?

O senso de desamparo e estresse vivenciado pelo desgaste 
do processo e pela dificuldade de assimilação da informação (ou a falta dela) desencadeia indignação e uma busca de culpados pelo problema da filha, como ilustram os trechos a seguir:

Na verdade, se a gente vai analisar, todos os médicos erraram, todo mundo... todo mundo errou, se eu sei um pouquinho... (...) Não sei se o cara serviu de cobaia... (...) Os médicos não sabem... (....) ....Uma hora dizem que vai ficar cega, outra hora já falam em grande grau de dificuldade de visão, já falaram diferente. (Pai)

$\mathrm{Na}$ literatura, há registros de indignação e raiva direcionadas à equipe de saúde nestas situações, seja por questões reais ou pela necessidade de deslocar a raiva para fora da família (Bradford, 1997).

A confusão vivenciada pelos pais em relação ao entendimento do diagnóstico fica clara no trecho a seguir:

Mãe: praticamente desde que a nenê tá doente me sinto sem as informações...

Pai: Não, eles falam rapidamente..., mas realmente saber entender, dizem: "tá bem!"

Mãe: Mas em que sentido tá bem? Que sentido? A retina foi colada? Não se formou?

Pai: O quê que é "tá bem a cirurgia"? (...) não digo que, não que vá enxergar normal, mas para se defender pelo menos.

Bradford (1997), ao explicar a importância da comunicação equipe de saúde-família para a adaptação dos pais no contexto da saúde, chama a atenção para a influência recíproca entre as crenças dos pais sobre a saúde do filho e a informação recebida dos profissionais. Problemas na comunicação comprometem a compreensão do quadro, gerando distorções e falsas expectativas. As ideias dos pais, em relação a terem servido de "cobaias" ou de não terem sido atendidos a tempo por questões financeiras, exemplificam essas distorções. Por outro lado, a frustração parental em relação à deficiência do filho e a própria parentalidade pode tomar uma forma ambivalente de relação com a equipe, conforme explica Bradford (1997). Ora sentem raiva das equipes de saúde, ora sentem-se confiantes com sua atuação.

Os pais recorrem à religião e aos médicos que, no entender deles, possam trazer novidades de pesquisas ou outras alternativas. Essa reação revela a questão da ambiguidade na relação com a equipe (confiança x desconfiança), constituindo-se também em uma estratégia para tentar adaptar-se aos desafios da situação. Para Bradford (1997), essas ações são mecanismos de coping, isto é, formas de lidar com o conflito, e focam tanto a emoção quanto a resolução de problemas.

Outro aspecto que aparece nas falas dos pais refere-se à culpa. Eles tentam repensar o que passou e se perguntam sobre o porquê dos acontecimentos, pensando no que eles podem ter "errado".

Todos os dias, não tem um dia que eu não faça a mesma pergunta: por que que aconteceu isto ou por que, que nem ele (marido) me pergunta: "Por que que eu não segurei mais a nenê na barriga, por que que eu não me cuidei mais na gravidez?" Sabe, é tudo por que, por que. E a gente não encontra resposta, sabe, durante a minha gravidez eu nunca tive uma dor de barriga para dizer "Ai foi disto que ela não segurou.” A gente não sabe, a gente vai deitar com as mesmas perguntas e levanta de manhã com as mesmas perguntas. "Por que que aconteceu?!?”É todos os dias com a mesma incerteza, com a mesma angústia... (Mãe)

Esse resultado é consistente com outros achados. Por exemplo, Rossel et al. (2002) referem que, em seu estudo, 75\% das mães se sentiam culpadas e impotentes, por sentirem-se de alguma forma responsáveis pela prematuridade do filho.

Os relatos apresentados mostram uma peculiaridade da descoberta do diagnóstico, o qual não se dá no momento do nascimento, mas durante a internação hospitalar. Isto é, vai sendo descoberta aos poucos. Como a medicina já tem tratamentos a oferecer para a ROP, assim como formas de prevenção da cegueira mediante diagnóstico precoce, os pais, ao se defrontarem com o problema, começam a ter esperança de solução. No entanto, a realidade do crescimento rápido do número de UTI's neonatais no mundo e o lento crescimento dos programas específicos de detecção e tratamento precoce da ROP (Quinn, 2007) também contribuem para a corrida a inúmeros centros e hospitais em busca do tratamento, o que aumenta o risco de o bebê não ser tratado a tempo e, consequentemente, o estresse vivido pela família. Como foi apontado por Mousavi et al. (2009), existe um período crítico para a detecção da ROP para que possa haver a prevenção da cegueira. Perceber que esse período crítico passou e a filha não foi examinada a tempo de poder receber os tratamentos adequados é, sem dúvida, extremamente doloroso para os pais, que buscam os culpados e tentam recuperar o tempo perdido.

A possibilidade de evitar a doença e o fato de esta família não ter conseguido se submeter ao tratamento que trazia esperanças de melhora para a visão da menina, conforme relataram os pais, parece ser um ponto importante nos sentimentos dessa família. Pode-se pensar na base da Psicologia da Saúde do modelo de Bradford (1997), a qual indica que nem toda doença crônica gera um desajuste na família, e é necessário identificar quais variáveis contribuem para um enfrentamento limitado da doença. Nesse sentido, o fato de haver UTI's que não seguem ainda as diretrizes indicadas em todas as unidades neonatais do país pelo Conselho Brasileiro de Oftalmologia e pela Sociedade Brasileira de Oftalmologia Pediátrica (Zin et al., 2007) aumenta o risco de cegueira por ROP no Brasil e faz com que a indignação dos pais seja maior do que o sentimento enfrentado por uma doença que não teria como ser evitada.

Essa realidade parece detê-los, muitas vezes, em um estágio de reações emocionais ao nascimento de uma criança com deficiência, descrito por Irvin et al. (1993), que fica entre o segundo (descrença) e o terceiro (tristeza, cólera e ansiedade), expresso na forma de uma "corrida aos médicos". Os autores consideram que esse estágio ocorre antes de os pais poderem sentir a dor da perda do filho "normal", antes da tristeza e da depressão. Pode aparecer a cólera voltada contra Deus, contra o destino, mas também contra a equipe hospitalar, amigos e parentes, pois, a despeito do que as pessoas façam para auxiliar os pais, nada é suficientemente apreciado, posto que o desejo real é poder "voltar atrás" e ter um filho "perfeito". Esse estágio poderia 
ser mais curto se os hospitais em nosso país, em especial no interior do Estado, oferecessem uma estrutura para a prevenção e o tratamento da ROP, uma vez que a busca de serviços na capital e as incertezas quanto ao diagnóstico e tratamento estão interrelacionadas com o alto grau de desamparo e de estresse vivenciados pela família participante neste estudo.

Os relatos fazem pensar nas questões trazidas por Drotar et al. (1975), quando falam das reações emocionais de descrença e negação em relação ao diagnóstico. A longa caminhada para compreender o diagnóstico pode estar refletindo a descrença na realidade da deficiência visual, demonstrando uma esperança irreal. Porém, por outro lado, a longa caminhada em busca da certeza do diagnóstico e de tratamentos alternativos pode também ser a demonstração desses pais de uma profunda aceitação da condição da filha e busca de uma melhor qualidade de vida para a mesma.

Contrastando com o estudo de Nobre et al. (2008), o casal mostrou fortemente os sentimentos de raiva e revolta. É possível que esse contraste esteja evidente em função do período de vida em que foram realizadas as entrevistas. No primeiro, os pais já lidavam com a realidade do diagnóstico da deficiência há anos. Diferentemente, o casal entrevistado parecia estar em plena vivência do recebimento da notícia, tentando ainda compreender o diagnóstico e, em especial, lutando contra o prognóstico.

O desenvolvimento de Kate e o dia-a-dia com o bebê: Frustração, preocupação e dúvida, falta de informações sobre a $D V$, as mudanças na rotina e medos

Analisando os relatos de Ana e Edson sobre o desenvolvimento de Kate, eles descrevem que em algumas áreas a filha está se desenvolvendo de acordo com a idade (com correção em função da prematuridade) e em outras ela apresenta algumas dificuldades. Apesar de vários aspectos estarem em pleno crescimento, os pais de Kate parecem, em alguns momentos, não acreditar no bom desenvolvimento que é possível para a menina e mostram-se frustrados. Isso se expressa em algumas falas como:

Se fosse de tempo normal hoje ela estaria com 11 meses né, então a gente imaginava ela segurando uma bolachinha na mão, querendo pegar as colheres sozinha para bater no prato, todas aquelas coisas assim, tudo que a gente quer, quer comer tudo que a gente quer e não é assim. Ela é teimosa para comer, é como ela quer, não é qualquer coisa que agrada, sabe, então, não é como a gente imaginou. (Mãe)

Os pais demonstram preocupação e dúvida em relação a questões de mobilidade.

“É, tendo um pouco de visão não vai se bater nas coisas? É isso que eu quero! (...) Se defendendo! Se defendendo... É isso que eu quero... Aí pago todas as promessas." (Pai)

Percebem que a deficiência da filha traz um modo diferente de comunicação, ao qual eles precisam estar atentos: "Uma criança normal vai dizer o que ela quer dizer, do modo de dizer... (...) Vai sinalizar, vai dar uma deixa do que ela vai fazer.(...) Então a gente não entende ainda o que ela quer dizer(...).” (Mãe)

Mostram dúvidas em relação ao que podem esperar do desenvolvimento da filha, quando se perguntam sobre o futuro de Kate:

Pai: E agora, o que vai ser da pequenininha? Ela vai ter a vida dela?

Mãe: Preocupação com o que vai ser da vida dela amanhã? Como que ela vai... Se ela vai aceitar...

Pai: ...ou se revoltar... (...)

A mãe relata que sua rotina mudou em relação à vida de casal e ao dia-a-dia com as atividades relacionadas à saúde da filha. O pai relata um aumento das preocupações:

"Muita preocupação com ela, como... a gente pensa uma coisa e agora é totalmente diferente, a gente ... filho normal ... o caminho é por aqui e tem que ir por aqui oh, é muito mais difícil (...), olha que ter filho não é fácil... muito difícil!..." (Pai)

Para Amiralian (1997), os pais, muitas vezes, ficam paralisados por pensarem que o mundo do cego é um mundo na escuridão, esquecendo-se de que, apesar de lhe faltar a visão, o cego se relaciona com o mundo externo por meio da audição, do tato, da gustação, do olfato e da cinestesia. Aparece a frustração ao se deparar com um desenvolvimento diferente do padrão esperado, pois, na DV, o desenvolvimento vai ocorrer de uma forma singular (Warren, 1994), pois a comunicação pelo olhar não é o parâmetro dessa relação. A comunicação pelo olhar, tão importante para direcionar a atenção na interação, necessita ser substituída por outras vias. Por fim, os medos relacionados ao futuro, além de mostrarem a natural preocupação dos pais de qualquer criança, podem estar interligados, entre outros fatores, à falta de informações sobre as reais capacidades de desenvolvimento de um indivíduo com DV e parecem ser uma preocupação recorrente nas famílias com crianças cujo desenvolvimento é atípico (Schmidt, 2004).

As falas mencionam o fato de terem que se responsabilizar por muitas tarefas, deixando a vida pessoal e conjugal em um segundo plano, como já foi descrito na literatura (Leyser et al., 1996., Lopes et al., 2009). Além disso, os pais de Kate se sentem despreparados para se comunicar com a menina. Aparece a dúvida em relação ao que a filha consegue lhes comunicar e ao que eles são capazes de compreender dos sinais dela, corroborando a literatura sobre os possíveis ciclos de interação assincrônica na interação e comunicação pais-bebê com DV (Kekelis \& Andersen, 1984). Por outro lado, os pais são capazes de perceber a capacidade de interação de seu bebê.

O esforço desses pais em compreender as comunicações do seu bebê é extremamente importante, uma vez que a criança cega já apresenta, de antemão, uma dificuldade de utilizar alguns comportamentos comunicativos, exigindo dos seus cuidadores uma capacidade diferenciada de leitura destes. Os pais necessitam ter uma habilidade acurada para compreender a comunicação alternativa fornecida por seu filho com deficiência visual.

Aprendendo a se reorganizar: A descoberta do prazer da parentalidade, a busca de apoio mútuo e construção de rede de apoio

Há momentos em que os pais referem prazer na parentalidade 
e se sentem compreendendo a filha: "Banho, a hora do banho é hora que mais gosto, que maravilha, (...) me deixa satisfeita porque é uma coisa que ela gosta.” (Mãe) “... Vamos bater perna?! Aí ela gosta!” (Pai)

Aparecem também momentos em que os pais reconhecem a capacidade de interação da filha: "Ah, a Kate quando escuta a voz da vó, ela já vai abrindo um sorriso (...) interação muito boa." (Mãe)

A mãe demonstra contentamento com a descoberta de seus próprios recursos e com suas possibilidades de superação, além da preocupação: “Ah, eu também me considero uma mãe bastante preocupada, sabe, muito dedicada a ela (...) me considero uma mãe assim uma super mãe, (...) tu te considera uma mulher maravilha..." (Mãe)

O casal busca apoio mútuo nos momentos difíceis, bem como o de outras pessoas: "Um apoia o outro em tudo e eu não faço nada sem a opinião dele e ele também sem a minha. (...) Muito apoio, muito mesmo, tem muita gente lá da comunidade, todo mundo vem dar força." (Mãe)

Os relatos mencionados mostram que os pais de Kate apresentam também reações emocionais da fase de reorganização. Aparecem preocupações e dor, mas os pais também parecem estar se organizando frente a realidade do diagnóstico. $\mathrm{O}$ fato de conseguirem levar a menina para o trabalho de estimulação precoce, específica para crianças com DV, mostra que a família já consegue encarar o diagnóstico.

Por vezes, a capacidade de parentalizar, ou seja, o senso de autoeficácia do casal como pais, mostra-se afetada. Eles ficam em dúvida sobre o próprio entendimento a respeito das comunicações da filha; consideram que ficam pouco tempo com ela, apesar de dedicarem-se diariamente. Esse é um ponto importante que aparece em relação a esse casal, uma vez que a literatura aponta que a confiança e a convicção da família em seu próprio potencial para auxiliar o filho é de grande importância para a habilidade familiar em solucionar os problemas que surgem (Schmidt, 2004). Ainda nessa linha, é considerado essencial manter a família confiante em seu potencial e no seu próprio poder de controle de decisões para o próprio bem-estar e o da criança (McDaniel, Hepworth, \& Doherty, 1994). Nesse sentido, parece que o apoio mútuo do casal está sendo um fator de grande importância para vencer os desafios oriundos da DV da filha.

Bowlby (1973/1998) refere que é comum surgirem conflitos entre os pais de um filho doente. Enquanto um está na busca de compreender melhor o prognóstico, o outro poderá estar negando a realidade, demonstrando irritação e negando apoio ao cônjuge. No entanto, o casal entrevistado parece estar conseguindo um apoio mútuo.

\section{Considerações finais}

Os resultados do estudo evidenciam diversos aspectos do impacto da prematuridade seguida de um diagnóstico de ROP, apoiando as premissas do modelo de Drotar et al. (1975). Entretanto, é possível perceber que os diferentes estágios são separados apenas do ponto de vista de apresentação. $\mathrm{Na}$ realidade, essas fases são profundamente interrelacionadas.
Outro dado consistente que aparece no presente estudo é que há um período no qual os pais não buscam atendimentos com foco no desenvolvimento da criança. Eles ficam primeiramente focados no diagnóstico e na busca de soluções para a patologia orgânica. É fundamental que a detecção da necessidade de intervenção seja mais rápida, pois o primeiro ano de vida é um período crítico para o desenvolvimento.

Cada vez mais, parece fundamental que haja uma articulação entre o serviço de Psicologia com outras áreas da saúde nos hospitais, para poderem intervir precocemente, ajudando os pais. Outro resultado importante é o que trata especificamente da dificuldade de interação entre os pais e a criança com deficiência visual. Considerando-se que a interação é a base do desenvolvimento global infantil, a intervenção direcionada para essas dificuldades parece ser urgente. De fato, estudos sobre as intervenções pais-bebê, neste contexto, são escassas tanto na literatura nacional quanto na internacional, apontando para uma área de investigação promissora.

Foi um achado peculiar, no presente estudo, o fato de o diagnóstico ser descoberto lentamente, até pelas características da doença. Uma vez que a presente pesquisa deteve-se apenas em uma entrevista, não foi possível verificar as mudanças do impacto na parentalidade no decorrer do crescimento do bebê. Futuros estudos poderiam focar na transformação das reações emocionais ao longo da descoberta do diagnóstico.

\section{Referências}

Amiralian, M. L. T. M (1997). Compreendendo o cego. Uma visão psicanalítica da cegueira por meio de desenhos-histórias. São Paulo: Casa do Psicólogo, FAPESP.

Andreani, G., Custódio, Z. A. O., \& Crepaldi, M.A. (2006). Tecendo as redes de apoio na prematuridade. Alethéia, 24, 115-126.

Andrew, M. J., \& Sullivan, P. B. (2010). Feeding dificulties in disabled children. Paediatrics and Child Health, 20(7), 321-326.

Arnold, L., Sawyer, A., Rabe, H., Abbott, J., Gyte, G., Duley, L., \& Ayers, S. (2013). Parents'first moments with their very preterm babies: A qualitative study. BMJ Open, 3, 1-9.

Bardin, L. (1977). Análise de conteúdo. Lisboa: Edições 70.

Bonotto, L. B., Moreira, A. T. R., \& Carvalho, D. S. (2007). Prevalência de retinopatia da prematuridade em prematuros atendidos no período de $1992-$ 1999 em Joinville (SC): Avaliação de riscos associados - "screening". Arquivos Brasileiros de Oftalmologia, 70(1), 55-61.

Bowlby, J. (1998). Apego e perda: Perda, tristeza e depressão (V. Dutra, Trad., $2^{\text {a }}$ ed., Vol. 3). São Paulo: Martins Fontes. (Obra original publicada em 1973)

Bradford, R. (1997). Children, families and chronic disease: Psychological models and methods of care. Londres: Routledge.

Brazelton, T. B. (1998). O desenvolvimento do apego: Uma família em formação. Porto Alegre: Artes Médicas.

Cramer, B., \& Palácio-Espasa, F. (1993). Técnicas psicoterápicas mãe/bebê. Porto Alegre: Artes Médicas.

Donohue, P., Maurin, E., Kimzey, L., Marilee, M., \& Strobino, D. (2008). Quality of life of caregivers of very low-birthweight infants. Birth, 35, 212-219.

Drotar, D., Maskiewicks, A., Irvin, N., Kennell, J., \& Klaus, M. (1975). The adaptation of parents to the birth of an infant with a congenital malformation: a hypothetical model. Pediatrics, 56(5), 710-716.

Ferrari, A., Piccinini, C., \& Lopes, R. (2007). O bebê imaginado na gestação: Aspectos teóricos e empíricos. Psicologia em Estudo, 12(2), 305-313.

Figueiredo, M. O., Paiva e Silva, R. B., \& Nobre, M. I. R. (2009). Diagnóstico 


\section{2}

de baixa visão em crianças: Sentimentos e compreensão de mães. Arquivos Brasileiros de Oftalmologia, 72(6), 766-770.

Forcada-Guex, M.; Borghini, A.; Pierrehumbert, B.; Ansermet, F., \& Muller-Nix, C. (2011). Prematurity, maternal, posttraumatic stress and consequences on the mother-infant relationship. Early Human Development, 87(1), 21-26.

Fortes Filho, J. B., Barros, C. K., Coelho da Costa, M., \& Procianoy, R. S. (2007). Results of a program for the prevention of blindness caused by retinopathy of prematurity in southern Brazil. Jornal de Pediatria, 83(3), 209-216.

Fortes Filho, J. B., Eckert, G. U., Valiatti, F.B., Coelho da Costa, M., Bonomo, P. P., \& Procianoy, R. S. (2009). Prevalência e fatores de risco para a retinopatia da prematuridade: Estudo com 450 pré-termos de muito baixo peso. Revista Brasileira de Oftalmologia, 68(1), 22-29.

Gilbert, C. (2008). Retinopathy of prematurity: A global perspective of the epidemics, population of babies at risk and implications for control. Early Human Development, 84, 77-82.

Irvin, N. A., Kennell, J. H., \& Klaus, M. H. (1993). Atendimento aos pais de um bebê com malformação congênita. In M. H. Klaus \& J. H. Kennell (Orgs.), Pais/bebê: A formação do apego (pp. 245-275). Porto Alegre: Artes Médicas.

Kekelis, L., \& Andersen, E. (1984) Family communication styles and language development. Journal of Visual Impairment \& Blindness, 78, 54-65.

Laplane, A., \& Batista, C. (2008). Ver, não ver e aprender: A participação de crianças com baixa visão e cegueira na escola. Cadernos Cedes, 28,209-228.

Leyser, Y., Heinze, A., \& Kapperman, G. (1996). Stress and adaptation in families of children with visual disabilities. Families in society, 77, 240-249.

Lopes, M., Salomão, S., Berezovsky, A., \& Tartarella, M. (2009). Avaliação da qualidade de vida relacionada à visão em crianças com catarata congênita bilateral. Arquivos Brasileiros de Oftalmologia, 72(4), 467-480.

McDaniel, S. H., Hepworth, J., \& Doherty, W. J. (1994). Terapia familiar médica: Um enfoque biopsicossocial às familias com problemas de saúde. POA: Artes Médicas.

Melamed, J. (2009). Contributions to the history of ocular toxoplasmosis in southern Brazil. Memorial Instituto Oswaldo Cruz. 104(2), 358-363.

Morisod-Harari, M., Borghini, A., Hohlfeld, P., Forcada-Guex, M., \& MullerNix, C. (2013). Influence d'une hospitalization prénatale sur les facteurs de stress parentaux lors d'une naissance premature. Journal de Gynécologie Obstétrique et Biologie de la Reproduction, 42(1), 64-70.

Mousavi, S. Z., Karkhaneh, R., Riazi-Esfahani, M., Mansouri, M. R., Roohipoor, R., Ghalichi, L., ... Naieri, F. (2009). Retinopathy of prematurity in infants with late retinal examination. Journal of Ophtalmic and Vision Research, 4(1), 24-28. doi: 10.1542/peds.2010-0090

Nobre, M. I. R. S., Montilha, R. C. I., \& Temporini, E. R. (2008). Mães de crianças com deficiência visual: percepções, conduta e contribuição do atendimento em grupo. Revista Brasileira de Crescimento e Desenvolvimento Humano, $18(1), 46-52$.

Nuernberg, A. (2008). Contribuições de Vigotsky para a educação de pessoas com deficiência visual. Psicologia em Estudo, 13(2), 307-316.

Quinn, G.(2007). Retinopatia da prematuridade no Brasil: Um problema emergente. Jornal de Pediatria, 83(3), 191-193.

Resnikoff, S., Pascolini, D., Etya'ale, D., Kocur, I., Pararajasegaram, R., Pokharel, G. P., \& Mariotti, S. P. (2004). Global data on visual impairment in the year 2002. Bulletin of the World Health Organization, 82(11), 844-851.

Rossel, K., Carreño, T., \& Maldonado, M. L (2002). Afectividad en madres de niños prematuros hospitalizados. Revista Chilena de Pediatria, 73(1), 15-21.

Schmidt, C. (2004). Estresse, auto-eficácia e o contexto de adaptação familiar de mães de portadores de transtornos globais do desenvolvimento. (Tese de Mestrado não publicada). Universidade Federal do Rio Grande do Sul: Porto Alegre.

Simmons, L. E., Rubens, C. E., Darmstadt, G. L., \& Gravett, M. G. (2011). Prevent preterm birth and neonatal mortality: Exploring the epidemiology, causes, and interventions. Seminars in Perinatology, 34(6) 408-415.

Soulé, M. (1987). O filho da cabeça, o filho imaginário. In T. Brazelton, B. Cramer, L. Kreisler, R. Schappy \& M. Soulé (Orgs.) A dinâmica do bebê. (pp.132-170). Porto Alegre: Artes Médicas.

Souza, C. M., \& Batista, C.G. (2008). Interação entre crianças com necessidades especiais em contexto lúdico: Possibilidades de desenvolvimento. Psicologia: Reflexão e Crítica, 21(3), 383-391.

Stern, D. N. (1997). A constelação da maternidade. Porto Alegre: Artes Médicas. Suaning, G. J., Lovell, N. H., Schindhelm, K., \& Coroneo, M. T. (1998). The bionic eye (electronic visual prosthesis): A review. Australian and New Zealand Journal of Ophthalmology, 26(3), 195-202.

Tröster, H. (2001). Sources of stress in mothers of young children with visual impairments. Journal of Visual Impairment \& Blindness, 10, 623-637.

Warren, D. H. (1994). Blindness and children: An individual differences approach. United States of America Cambridge University Press.

World Health Organization (WHO) (1993). International Statistical Classification of Diseases, Injuries and causes of Death, tenth revision. Geneve.

World Health Organization (WHO) (1999). Mother and health: Mainstreaming the gender perspective into the health sector. [Report of the Expert Group Meeting, 28 September-2 October, 1998.], United Nations, Tunis, Nova Iorque.

Zin, A., Florêncio, T., Fortes Filho, J. B., Nakanami, C. R., Gianini, N. Graziano, R. M., \& Moraes, N. (2007). Proposta de diretrizes brasileiras do exame e tratamento da retinopatia da prematuridade (ROP). Arquivos Brasileiros de Oftalmologia, 70(5), 875-883. 
1. Este estudo está inserido em um projeto maior, de doutorado da autora, sobre a efetividade de uma intervenção com enfoque na comunicação/interação pais/bebê com Deficiência Visual (Comitê de Ética Proc No 06/610).

2. Olho biônico (prótese visual-eletrônica): Caracteriza-se por um receptor eletrônico a ser implantado e instalado no globo ocular do deficiente visual, que por sua vez, é ligado ao nervo óptico e a óculos especiais. Nesses óculos, encontra-se ligada uma câmera que capta a imagem, enviando-a para um processador portátil, que transforma a imagem em sinais eletrônicos, enviando-os para o receptor. Logo, este vai emitir impulsos à retina, possibilitando um certo grau de visão (http://www.todosnos.unicamp.br:8080/lab/usuario-de-protese-ganha-sensibilidade-em-dedo-artificial). Segundo Suaning, Lovell, Schindhelm e Coroneo (1998), os benefícios do olho biônico para a população com deficiência visual ainda são limitados.

Carla Meira Kreutz, Doutora em Psicologia pela Universidade Federal do Rio Grande do Sul (UFRGS) e San Francisco State University (SFSU - USA), é professora Adjunta na Universidade Luterana do Brasil (ULBRA/Campus Gravataí). Endereço para correspondência: Rua Ramiro Barcelos 2600/Térreo/Secretaria do Pós-Graduação em Psicologia, Porto Alegre-RS. CEP: 90035-003. Telefones: (51) 9957-2323 ou (51) 3308-5261 ou (51) 3308-5246. Fax: (51) 3308-5473. E-mail: carla.kreutz@gmail.com

Cleonice Alves Bosa, PhD em Psicologia pelo Instituto de Psiquiatria da Universidade de Londres, Inglaterra e Pós-Doutora em Transtornos do Desenvolvimento pela Universidade de Cincinnati, USA, é professora Associada na Universidade Federal do Rio Grande do Sul (UFRGS).E-mail: cleobosa@uol.com.br 